\title{
Circulating specific biomarkers in diagnosis of hepatocellular carcinoma and its metastasis monitoring
}

\author{
Li Wang • Min Yao • Zhizhen Dong • Yun Zhang • \\ Dengfu Yao
}

Received: 22 July 2013 / Accepted: 23 August 2013 / Published online: 5 September 2013

(C) The Author(s) 2013. This article is published with open access at Springerlink.com

\begin{abstract}
Hepatocellular carcinoma (HCC) is one of the most common and rapidly fatal malignancies worldwide with a multifactorial, multistep, complex process and poor prognosis. Its early diagnosis and metastasis monitoring are of the utmost importance. Hepatoma tissues synthesize various tumor-related proteins, genes, enzymes, microRNA, etc. and then secrete into the blood. Detections of circulating biomarkers are useful to find tumor at an early stage or monitor metastasis after postoperative treatment. This paper summarizes recent studies of specific biomarkers at early diagnosis or in monitoring metastasis or postoperative recurrence of HCC.
\end{abstract}

Keywords Hepatocellular carcinoma - Specific biomarkers · Diagnosis $\cdot$ Monitoring metastasis $\cdot$ Postoperative recurrence

Li Wang and Min Yao contributed equally to this work.

L. Wang $\cdot$ D. Yao $(\bowtie)$

Research Center of Clinical Medicine, Affiliated Hospital of Nantong

University, Nantong 226001, Jiangsu Province, China

e-mail: yaodf@ahnmc.com

\section{Wang}

Department of Medical Informatics, Medical School of Nantong

University, Nantong 226001, Jiangsu Province, China

M. Yao

Department of Medical Immunology, Medical School of Nantong

University, Nantong 226001, Jiangsu Province, China

\section{Z. Dong}

Department of Diagnostics, Affiliated Hospital of Nantong

University, Nantong 226001, Jiangsu Province, China

\section{Y. Zhang}

Institute of Medicine, Nanjing Medical University, Nanjing 210029,

Jiangsu Province, China

$\begin{array}{ll}\text { Abbreviations } \\ \text { GPC-3 } & \text { Glypican-3 } \\ \text { HBV } & \text { Hepatitis B virus } \\ \text { HCC } & \text { Hepatocellular carcinoma } \\ \text { HCV } & \text { Hepatitis C virus } \\ \text { HS-AFP } & \text { HCC-specific AFP } \\ \text { HS-GGT } & \text { HCC-specific gamma-glutamyltransferase } \\ \text { HSP } & \text { Heat shock protein } \\ \text { IGF } & \text { Insulin-like growth factor } \\ \text { miRNA } & \text { MicroRNA } \\ \text { PBMC } & \text { Peripheral blood mononuclear cell } \\ \text { PCR } & \text { Polymerase chain reaction } \\ \text { TGF } & \text { Transforming growth factor }\end{array}$

\section{Introduction}

Hepatocellular carcinoma (HCC) is the third deadliest and fifth most common cancer worldwide [1, 2]. HCC ranks the second in China among all malignancies, and its mortality is almost equal to its morbidity. Carcinogenesis of HCC is a multifactor, multistep, complex process, which is associated with a background of chronic liver diseases or persistent infection of hepatitis B virus (HBV) or hepatitis C virus (HCV), along with alcohol and aflatoxin B1 intake which are widely recognized etiological agents in $\operatorname{HCC}[3,4]$. However, the underlying mechanisms that lead to malignant transformation of infected cells remain unclear. Most of HCC patients died quickly because of the rapid tumor progression, and hepatic resection or transplantation is the only potential curative treatment for HCC patients [5]. Although the mortality of HCC has significantly decreased with the development of surgical techniques, about $60 \sim 100 \%$ of the patients suffered from HCC recurrence ultimately even after curative 
resection, and it has become the most important factor that limits the long-term survival of HCC patients [6].

The most urgent needs are to find sensitive markers for early diagnosis or monitor postoperative recurrence and to give adequate treatment for HCC. It has many characteristics, such as fast infiltrating growth, metastasis in early stage, highgrade malignancy, and poorly therapeutic efficacy, with the prognosis that is poor and early detection that is of the utmost importance [7]. Although serum alpha-fetoprotein (AFP) level is a useful tumor marker for the detection and monitoring of HCC, the false negative rate with AFP level alone may be as high as $40 \%$ for patients with early stage HCC. Even in patients with advanced HCC, the AFP levels may remain normal in $15 \sim 30 \%$ of the patients [8]. New specific markers $[9,10]$, such as circulating HCC-specific gammaglutamyltransferase (HS-GGT) [5], HCC-specific AFP (HSAFP or AFP-L3) [11, 12], microRNA (miRNA) [13], glypican-3 (GPC-3) [14], and Golgi glycoprotein 73 [15, 16], have been developed to improve the sensitivity, specificity, early detection, and prediction of prognosis. However, the overall results have been unsatisfactory $[17,18]$. The present article summarizes recent studies of the specific molecular markers in early diagnosis and monitoring metastasis or postoperative recurrence of HCC.

\section{Hepatoma-specific AFP and AFP-messenger RNA}

AFP, a 70-kD glycoprotein synthesized from the fetal yolk sac, liver, and intestines, has a half-life of 5 7 days. Total serum AFP level is a prognostic indicator of the response and survival of germ cell tumors [19]. However, when an AFP level is slightly elevated, it may be falsely elevated owing to nonneoplastic liver disease [20]. Although total AFP is a useful serological marker for HCC diagnosis, the false negative rate or false positive rate with AFP level alone may be as high as $40 \%$, especially for its early diagnosis or the finding of small size $\mathrm{HCC}(<2 \mathrm{~cm})$. It is sometimes very difficult to make the distinction between tumors and falsely elevated AFP levels because of benign liver diseases (Fig. 1a, b) [21]. Recently, the separation of a HS-AFP subfraction has been reported to be superior to total AFP level in both sensitivity and specificity in differentiating between benign and malignant liver diseases [22].

Total AFP can be divided into three different glycoforms (Fig. 1c), AFP-L1, AFP-L2, and AFP-L3 (Fig. 1d), according to their binding capacity for lens culinaris agglutinin (LCA) or their isoelectric point difference. HS-AFP, as the LCA-bound fraction, is the major glycoform of AFP in the sera of HCC patients. Early diagnosis is very important for HCC. With a HS-AFP of more than $15 \%$, the levels of serum AFP and HSAFP in $\mathrm{HCC}$ were significantly higher than those in other liver diseases [23]. Although total AFP level in liver cirrhosis was significantly higher than that in chronic hepatitis or normal control, no significant relationship was found between the percentage of HS-AFP and total AFP level, HBsAg-positive or HBsAg-negative status, tumor size, or number. However, there was a relationship with HCC differentiation, metastasis, and relapse, suggesting that the percentage of HS-AFP may be a more specific marker than total AFP for early diagnosis and recurrence of HCC [24-26].

The genetic markers or tumor-specific protein can monitor carcinogenesis of hepatocytes and can diagnose HCC at an early stage of HCC development. Angiogenesis is necessary for solid tumors larger than $1 \times 1 \mathrm{~mm}$; otherwise, the tumor remains dormant and does not metastasize [25]. As soon as it enters the angiogenesis stage, metastasis potency is exhibited. AFP messenger RNA (mRNA) from peripheral blood mononuclear cells (PBMCs) by reverse transcription-polymerase chain reaction (PCR) has been most extensively studied in recent years (Fig. 2). Using the appropriate single tumor marker or combination of other markers may improve the effectiveness in screening HCC patients [27, 28]. If HCCspecific mRNAs are detected in the circulating blood, it is possible to infer the presence of circulating, presumably malignant liver cells and to predict the likelihood of hematogenous metastasis. By now, many clinical, tumor genetic and molecular biological markers have been used to diagnose $\mathrm{HCC}$ or to predict $\mathrm{HCC}$ recurrence, but it is a frequently encountered situation that different conclusions were drawn from different researches concerning the value of the same predictor. As circulating cancer cells are an important source for HCC metastasis, the biomarkers that indicate the malignant cell existence may be a useful predictor for HCC extrahepatic metastasis $[29,30]$.

\section{HS-GGT isoforms}

GGT (Enzyme Commission number 2.3.2.2) is a membranebound enzyme that catalyzes the degradation of glutathione and other gamma-glutamyl compounds by hydrolysis of the gamma-glutamyl moiety or by its transfer to a suitable acceptor $[31,32]$. This enzyme exhibits a tissue-specific expression that is modified under various physiologic and pathologic conditions, such as development and carcinogenesis. It is highest in the embryo livers and decreases rapidly to the lowest levels after birth, and it is a widely distributed enzyme that has been extensively studied in relation to hepatocarcinogenesis. GGT is a heterodimeric glycoprotein [33, 34], and its total activity in patients with liver diseases and extrahepatic tumors was abnormally increased. Several studies have demonstrated that these increases are often associated with structural changes of its sugar chains, as evidenced by a variation in the pattern of serum GGT isoforms, suggesting that evaluations of GGT multiple forms might improve the specificity of GGT measurement and 
Fig. 1 Immunohistochemical staining of hepatic AFP expression and molecular features in HCC. a AFP in HCC tissues $(\mathrm{SP}, \times 400)$. b AFP in precancerous tissue (SP, $\times 400)$. c AFP isoelectric point $(p I)$ from different tissues. $\mathbf{d}$ The separation of AFP-L3 by a minicolumn chromatography
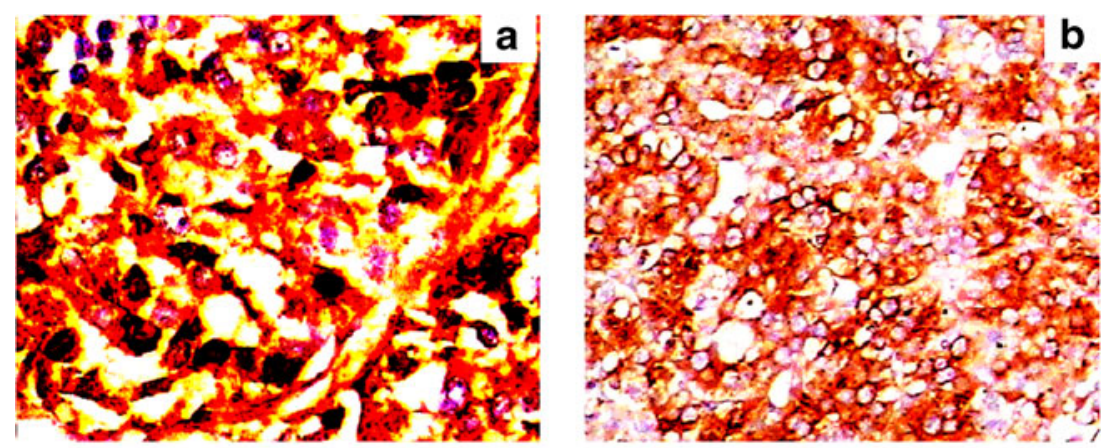

AFP $+111, p \mid 4.90$

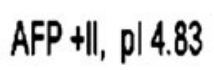

AFP $+1, p \mid 4.78$ c

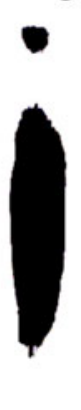

d

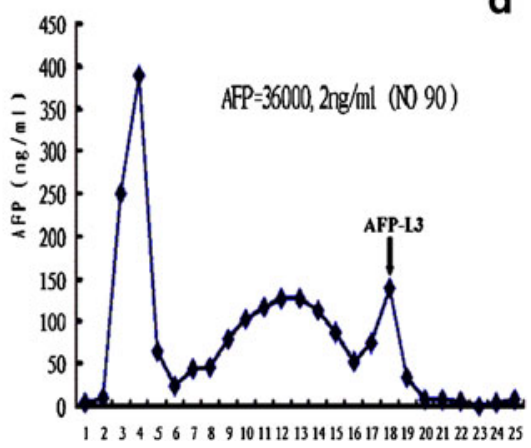

that there might be a correlation between specific patterns and different disease states $[35,36]$.

GGT is re-expressed during the HCC development and can be divided into several subfractions according to different electrophoresis mobility. HS-GGT bands (including I', II, and II') in sera of HCC patients can be separated by a vertical slab electrophoresis assay of polyacrylamide stage gradient gel and have been used in HCC diagnosis [37, 38]. Hepatic GGT with alteration of the gene methylation status is re-expressed during the HCC development. HS-GGT is a part of total GGT activity that can only be found in sera of HCC patients and has been confirmed as a useful specific molecular marker, and its analysis may improve the specificity and sensitivity of HCC diagnosis. The circulating HS-GGT activity was significantly elevated in the HCC patients with an incidence of $86 \%$ at the level of over $5.5 \mathrm{IU} / \mathrm{L}$ and in patients with other liver diseases with an incidence of $<3 \%$ (Fig. 3) [39].

From cancer to noncancerous tissues, an increasing tendency of total RNA expression was found [40, 41]. The frequencies of the amplified fragment and the hypomethylated M3 site of GGT genes were 100 and $75 \%$ in HCC tissues, 85 and $55 \%$ in paracancerous tissues, and 75 and $50 \%$ in noncancerous tissues, respectively. An inverse correlation was found between methylational degrees of GGT genes and GGT levels. The abnormal alteration of serum HS-GGT level is a sensitive tumor marker for diagnosis or differentiation of HCC, and its overexpression in HCC may be related to the gene hypomethylational status of CCGG sites [39].

According to the greatest HCC dimension, there are two groups of patients: $<5 \mathrm{~cm}$ and $>5 \mathrm{~cm}$. The diagnostic values of
AFP and HS-GGT levels were $42 \%$ in AFP and $76 \%$ in HSGGT for small size HCC and $83 \%$ in AFP and $92 \%$ in HSGGT for large size HCC, respectively. The abnormal frequency in the $<5 \mathrm{~cm}$ group was significantly higher $(P<0.01)$ in HS-GGT than that in AFP. A significant correlation was found between AFP levels and tumor size $(P<0.01)$. According to AFP levels $(<50,51 \sim 499,500 \sim 999$, and $>1,000 \mathrm{ng} / \mathrm{mL})$, the frequency of HS-GGT activity $>5.5 \mathrm{IU} / \mathrm{mL}$ in $\mathrm{HCC}$ was 79.6 , 96.4, 88.9, and $86.9 \%$, respectively. The HS-GGT positive rate was 79.6 or $89.7 \%$ in the $\mathrm{AFP}<50$ or $>50 \mathrm{ng} / \mathrm{mL}$ group. No significant relation was found between AFP level and HSGGT activity. However, the positive AFP could be found in HCC with low HS-GGT levels. A comparative analysis of HS-GGT and AFP markers for HCC diagnosis is shown in Table 1. The sensitivity, specificity, positive predictive or negative predictive value, and accuracy of HS-GGT quantitative analysis in HCC diagnosis were superior to the same values for AFP marker [39].

\section{Glypican-3 and its gene transcription}

GPC-3 is a membrane-anchored heparin sulfate proteoglycan normally expressed in the fetal liver and placenta, but not in the normal adult liver [42, 43]. It is an oncofetal antigen that is a reliable circulating biomarker for HCC and has not been observed in benign liver lesions by in situ hybridization or immunohistochemistry [44]. High-grade dysplastic nodules typically express GPC-3 in a weak and focal fashion, although the results have not been consistent across different series 

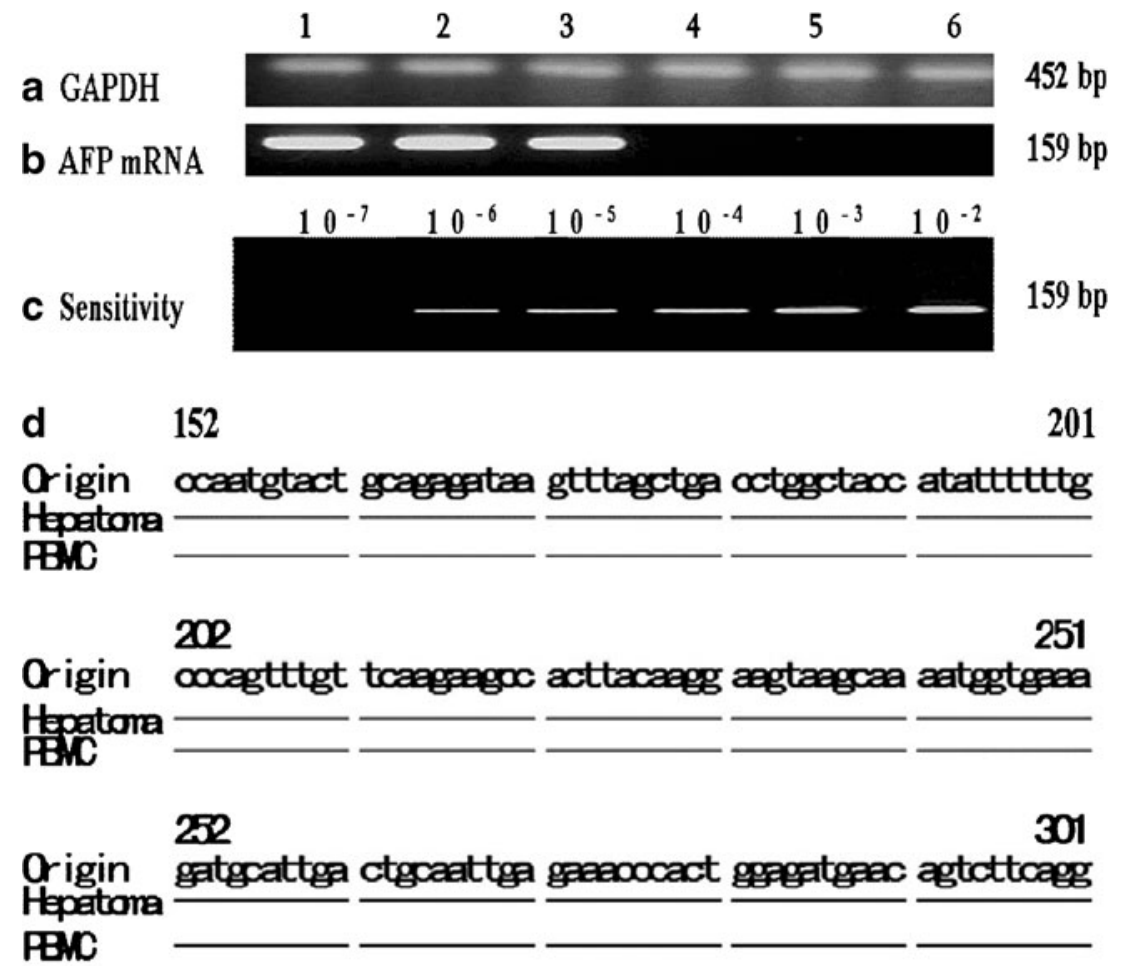

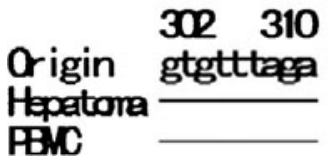

Fig. 2 Amplification of AFP messenger RNA ( $m R N A)$ from the livers or PBMCs and the alignment of amplified sequences. a The glyceraldehyde-3-phosphate dehydrogenase $(G A P D H)$ genome were used as a control. b The amplification of AFP genomes. Lanes 1 and 2 indicate positive AFP fragments from HCC tissues; 3, positive AFP fragments from paracancerous tissue; 4 , negative result from noncancerous tissue; 5

[45]. GPC-3 expression in hepatocarcinogenesis was previously investigated by rat HCC models, with the brown positive GPC-3 expression mainly distributed in cytosol, and membrane, with $100 \%$ in precancerous or cancerous tissues, and was associated with hepatocyte malignant transformation

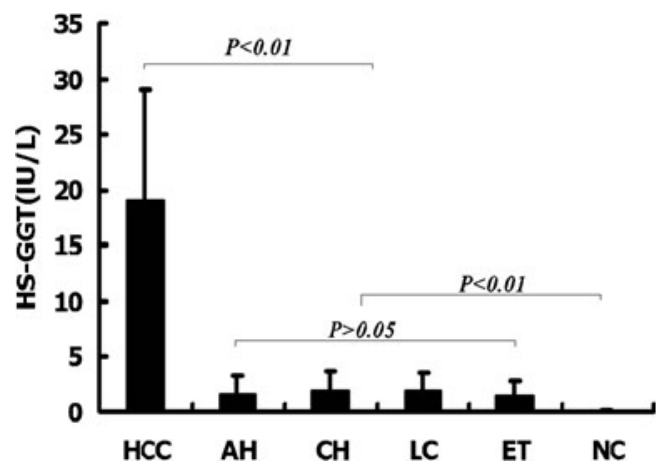

Fig. 3 Diagnostic values of circulating HS-GGT activities in sera of patients with liver diseases or extrahepatic tumors. $A H$ acute hepatitis, $C H$ chronic hepatitis, $L C$ liver cirrhosis, ET extrahepatic tumor, $N C$ normal controls and 6, negative result from circulating PBMCs of patients with liver cirrhosis or chronic hepatitis. $c$ The limitation for AFP mRNA analysis was $2 \mathrm{ng} / \mathrm{L}$ in the detection system. $d$ Alignment of nucleotide sequences of the amplified fragments of AFP genome in hepatoma or PBMCs from HCC patients. Origin: the cited sequence of AFP genome; Hepatoma: hepatoma tissue; PBMCs: blood from HCC patient

that it is an early biomarker for HCC. The expression and distribution of liver GPC-3 analyzed by immunohistochemistry with anti-GPC-3 antibody are shown in Fig. 4. The positive GPC-3 expression showed brown particles and located in cytosol and cell membrane with only a few in cellular nuclei with its diffusely staining in cancerous tissues (Fig. 4a) significantly higher than that in their paracancerous or distal

Table 1 Relation between AFP levels and HS-GGT activities

\begin{tabular}{llll}
\hline AFP $(\mathrm{ng} / \mathrm{mL})$ & No. & \multicolumn{2}{l}{$\operatorname{HS}-$ GGT $(>5.5 \mathrm{IU} / \mathrm{L})$} \\
\cline { 3 - 4 } & & Positive (\%) & Negative (\%) \\
\hline$<50$ & 49 & $39(79.6)$ & $10(20.4)$ \\
$51 \sim 499$ & 28 & $27(96.4)$ & $1(3.6)$ \\
$500 \sim 999$ & 18 & $16(88.9)$ & $2(11.1)$ \\
$>1,000$ & 61 & $53(86.9)$ & $8(13.1)$ \\
Total & 156 & $135(86.5)$ & $21(13.5)$ \\
\hline
\end{tabular}

$H S$-GGT hepatoma specific $\gamma$-glutamyltransferase, $A F P$ alpha-fetoprotein 
Fig. 4 Immunohistochemical staining and Western blotting analysis of hepatoma GPC-3 expression. a The GPC-3-positive cytoplasm in cancerous tissues. b GPC-3 in positive cancerous or negative paracancerous tissues (SP, $X$ 200). c The analysis of liver GPC-3 expression by Western blotting. Lanes 1-4 indicate liver tissues from HCC patients. HCC: the cancerous tissues; Para-can: their paracancerous tissues; Discan: their distal cancerous tissues
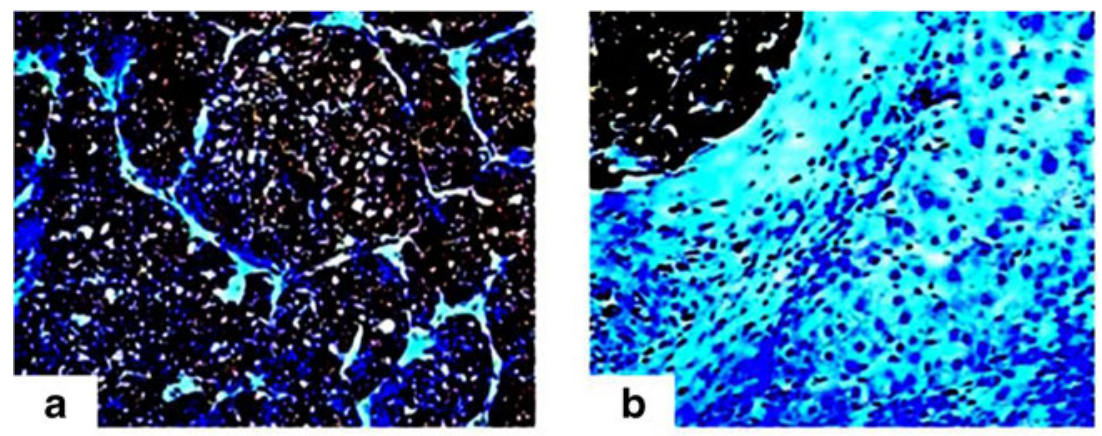

C
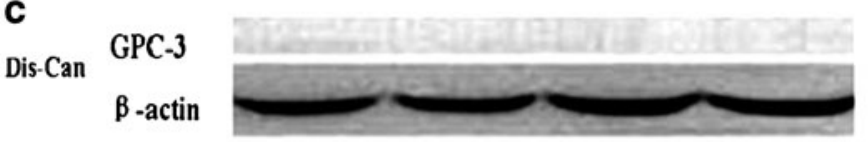

$55 \mathrm{KD}$

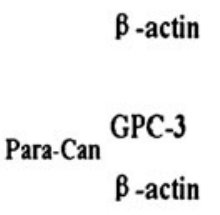

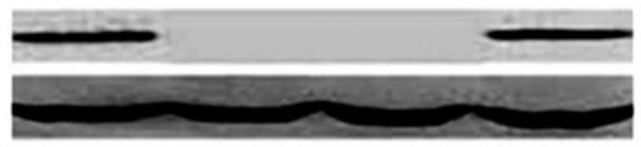

HCC $\quad$ GPC-3
$\quad \beta$-actin

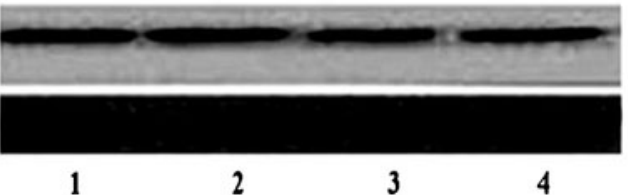

Line

1

2

3
$55 \mathrm{KD}$

$42 \mathrm{KD}$

$55 \mathrm{KD}$

$42 \mathrm{KD}$

$42 \mathrm{KD}$

Size cancerous tissues (Fig. 4b), indicated that the positive GPC-3 was markedly increased with specific expression in HCC confirmed by Western blotting (Fig. 4c) [46].

The incidence of GPC-3 expression in HCC group $(80.6 \%)$ was significantly higher than that in paracancerous or distal cancerous groups $(P<0.001)$, with the paracancerous group significantly higher than that in the distal cancerous group $(P<0.001)$. The clinicopathological characteristics demonstrated that no significant difference was found between GPC-3 intensity and differentiation degree, age, gender, tumor number, and AFP levels except that between tumor size ( $>3$ vs. $<3 \mathrm{~cm}, P<0.05$ ) and HBV infection (Table 2). The fragment of GPC-3 mRNA in PBMCs and cancerous and paracancerous tissues can be amplified and confirmed by sequencing, but not in distal cancerous tissues or PBMCs from cases with benign liver diseases [43, 47].

The incidence of circulating GPC-3 mRNA was $70.7 \%$ in HCC and $2.0 \%$ in cases with benign liver diseases or nonliver tumors. The significant higher incidence of GPC-3 mRNA was found in HCC patients with I and II vs. III and IV staging, HBV infection, and small size tumor, especially in HCC patients with the periportal cancer embolus or the extrahepatic metastasis group higher than that the without periportal cancer embolus or extrahepatic metastasis group (Table 2) [48, 49]. The quantitative GPC-3 levels showed that only GPC-3 was overexpressed in HCC (52.8\%) and $1.4 \%$ in cases with benign liver diseases or $2.0 \%$ in non-liver tumors, with significant differences between the HCC group and each of the study groups. The non-GPC-3 expression in sera of cases with benign liver diseases was detected except of one case with cirrhosis. There were no false positives among patients with acute or chronic hepatitis or among healthy subjects. However, in compared with AFP for HCC diagnosis, the higher positive result (up to $20.0 \%$ ) of AFP could be found in benign liver diseases, although the AFP positive rate was higher (70.73\%). According to tumor size, the abnormal frequency of serum GPC-3 was significantly higher $(P<0.01)$ in the $<3 \mathrm{~cm}$ group $(80.0 \%)$ than that in the $>3 \mathrm{~cm}$ group $(41.7 \%)$.

The combining diagnostic values of circulating GPC-3, GPC-3 mRNA, and AFP levels for HCC are shown in Table 3. The positive rate in $123 \mathrm{HCC}$ patients was $52.8 \%$ in serum GPC-3, $70.7 \%$ in positive GPC-3 mRNA from circulating $\mathrm{PBMC}$, and $70.7 \%$ in AFP. Total positive rates of circulating GPC-3 and its gene in combination with AFP could rise up to $94.3 \%$ for $\mathrm{HCC}$ diagnosis. The detecting GPC-3 and GPC-3 mRNA were superior to AFP in sensitivity, specificity, positive predictive or negative predictive value, and accuracy for HCC. The detection of circulating GPC-3 or its gene transcription in $\mathrm{HCC}$ specificity was superior to serum AFP alone, with efficacious in HCC differentiating diagnosis or monitoring hematogenous metastasis. Both combining applications of GPC-3 and AFP should rise up the HCC diagnostic sensitivity [50]. 
Table 2 The pathological characteristics of circulating GPC-3 mRNA in PBMCs from HCC patients

\begin{tabular}{|c|c|c|c|c|c|}
\hline \multirow[t]{2}{*}{ Group } & \multirow[t]{2}{*}{ No. of cases } & \multicolumn{2}{|l|}{ GPC-3 } & \multirow[t]{2}{*}{$x^{2}$} & \multirow[t]{2}{*}{$P$} \\
\hline & & Positive & Negative & & \\
\hline \multicolumn{6}{|l|}{ Sex } \\
\hline Male & 103 & 74 & 29 & 0.379 & 0.538 \\
\hline Female & 20 & 13 & 7 & & \\
\hline \multicolumn{6}{|l|}{ Age } \\
\hline$\geq 60$ years & 56 & 39 & 17 & 0.059 & 0.808 \\
\hline$<60$ years & 67 & 48 & 19 & & \\
\hline \multicolumn{6}{|l|}{ TNM staging } \\
\hline I and II & 47 & 39 & 8 & 5.551 & 0.019 \\
\hline III and IV & 76 & 48 & 28 & & \\
\hline \multicolumn{6}{|l|}{ Tumor size } \\
\hline$\geq 3.0 \mathrm{~cm}$ & 98 & 65 & 33 & 4.520 & 0.034 \\
\hline$<3.0 \mathrm{~cm}$ & 25 & 22 & 3 & & \\
\hline \multicolumn{6}{|c|}{$\mathrm{AFP}(\mathrm{ng} / \mathrm{mL})$} \\
\hline$\geq 400$ & 52 & 36 & 16 & 0.098 & 0.754 \\
\hline$<400$ & 71 & 51 & 20 & & \\
\hline \multicolumn{6}{|l|}{ HBsAg } \\
\hline Positive & 89 & 79 & 10 & 50.571 & $<0.001$ \\
\hline Negative & 34 & 8 & 26 & & \\
\hline \multicolumn{6}{|c|}{ Tumor number } \\
\hline Single & 58 & 40 & 18 & 0.165 & 0.685 \\
\hline Multiple & 65 & 47 & 18 & & \\
\hline \multicolumn{6}{|l|}{ Child-Pugh } \\
\hline A & 60 & 40 & 20 & 1.005 & 0.605 \\
\hline B & 45 & 34 & 11 & & \\
\hline $\mathrm{C}$ & 18 & 13 & 5 & & \\
\hline \multicolumn{6}{|c|}{ Periportal cancer embolus } \\
\hline With & 44 & 44 & 0 & 28.347 & $<0.001$ \\
\hline Without & 79 & 43 & 36 & & \\
\hline \multicolumn{6}{|c|}{ Extrahepatic metastasis } \\
\hline With & 65 & 65 & 0 & 57.019 & $<0.001$ \\
\hline Without & 58 & 22 & 36 & & \\
\hline
\end{tabular}

Table 3 Combining diagnostic values of circulating GPC-3, GPC-3 mRNA, and AFP levels for HCC

\begin{tabular}{lllll}
\hline & GPC-3 & GPC-3 mRNA & AFP & Total \\
\hline Sensitivity (\%) & 52.8 & 70.7 & 70.7 & 94.3 \\
Specificity (\%) & 98.8 & 99.8 & 86.2 & 85.8 \\
Diagnostic accuracy (\%) & 83.5 & 89.4 & 81.0 & 88.6 \\
Positive predictive value (\%) & 95.6 & 96.7 & 71.9 & 76.8 \\
Negative predictive value (\%) & 80.7 & 87.1 & 85.5 & 96.8 \\
\hline
\end{tabular}

${ }^{\mathrm{a}}$ AFP level was more than $20 \mathrm{ng} / \mathrm{mL}$

\section{Transforming growth factor- $\beta_{1}$ and its mRNA}

Transforming growth factor (TGF)- $\beta$ is a family of related proteins that regulate many cellular processes including growth, differentiation, extracellular matrix formation, and immunosuppressant [51]. Every cell in the body, including epithelial, endothelial, hematopoietic, neuronal, and connective tissue cells, produces TGF- $\beta$ and has receptors for it. TGF- $\beta_{1}$ is one of TGF- $\beta$ isoforms (TGF- $\beta_{1-5}$ ) and arrests the cell cycle in the G1 phase, thereof eliciting inhibition of cell proliferation and triggering apoptosis $[52,53]$. In normal liver tissues, TGF- $\beta_{1}$ is produced only by nonparenchymal cells (Kupffer's cell, fat storing cell, and endothelial cell). Previous studies have shown upregulated expression of TGF- $\beta_{1}$ in tumor cells, including HCC. Though a growth inhibitor, the overexpression of hepatic TGF- $\beta_{1}$ was found in HCC tissues and correlated with carcinogenesis, progression, and prognosis of $\mathrm{HCC}[3,54,55]$. TGF- $\beta_{1}$ expression was increased as the $\mathrm{HBV}$-induced disease progressed from chronic liver diseases to cirrhosis and then to HCC. In in vitro study, immunohistochemistry and in situ hybridization revealed that normal hepatocytes had not any TGF- $\beta_{1}$ staining $[56,57]$, but hepatocytes in regenerative and cirrhotic livers and HCC cells expressed different degrees of TGF- $\beta_{1}$ and its mRNA.

As the longevity of liver cirrhosis and HCC cells was observed compared to normal hepatocytes, it is plausible to propose that TGF- $\beta_{1}$ up-expression in these tumor cells is closely related to the cell survival, thereof possibly escaping the control of cell proliferation by TGF- $\beta$ [58]. The incidence of hepatic TGF- $\beta_{1}$ expression was higher in HCC (83\%) and lower in their surrounding tissues, and the incidence was $95 \%$ in positive HBV-DNA group and $64 \%$ in negative HBV-DNA one, respectively. TGF- $\beta_{1}$ expression is associated with HCC differentiation degree and status of $\mathrm{HBV}$ replication, but neither to tumor size nor to number. The levels of circulating TGF- $\beta_{1}$ and TGF- $\beta_{1}$ mRNA were significantly higher in HCC than those in any of other patients. Sensitivity or specificity of circulating TGF- $\beta_{1}$ level $(>1.2 \mu \mathrm{g} / \mathrm{L})$ was 90 or $94 \%$ for HCC diagnosis, but no significant correlation was found between TGF- $\beta_{1}$ and AFP expression or tumor sizes. Combining TGF- $\beta_{1}$ and AFP could raise the positive rate up to $97 \%$. Both of circulating TGF- $\beta_{1}$ and its mRNA could be used as sensitive biomarkers for the diagnosis or prognosis of HBV-induced HCC [59, 60].

\section{Insulin-like growth factor-II and its mRNA}

Insulin-like growth factor (IGF)-II is a mitogenic polypeptide closely related to insulin, and its gene has a complex regulation of transcription, resulting in multiple mRNAs initiated by different promoters [61, 62]. IGF-II is speculated to serve as an autocrine growth factor in various cancers with increasing IGF-I receptor, and it is a kind of fetal growth factor, and highly 
abnormality in hepatocarcinogenesis and re-expression of its gene has recently been described in HCC [63, 64]. HCC is generally considered to be a hypervascular tumor. Although hepatic arterial embolization is widely used as an effective treatment of HCC on the basis of HCC hypervascularization, IGF-II may play an important role in the development of HCC neovascularization, because IGF-II substantially increases vascular endothelial growth factor (VEGF) at mRNA or protein levels in a time-dependent manner [63, 65].

$\mathrm{HCC}$ is a common malignant disease with poor prognosis. Underlying molecular mechanism provides a potential to develop new therapeutic target, which is very urgent. The induction of VEGF by IGF-II was additively increased by hypoxia, and IGF-II may be a hypoxia-inducible angiogenic factor in $\mathrm{HCC}$ and stimulates the growth of HCC cells in vitro. Most of cirrhotic and HCC tissues express IGF-II (Fig. 5). However, little is known of its circulating IGF-II gene in HCC $[66,67]$. The positive frequencies of IGF-II mRNA were $100 \%$ in $\mathrm{HCC}$, half in paracancerous or none in noncancerous tissues, respectively. The circulating free IGF-II levels were significantly higher in HCC than those in chronic liver disease. IGFII abnormally expressed during HCC development [65]. Recent studies revealed that circulating IGF-II mRNA correlated well with the presence of extrahepatic metastases in HCC patient. The role of IGF-II in HCC cell proliferation and antiapoptosis is well established. Specific and efficient miRNA inhibited the IGF-II expression for exploring the effect of IGF-II inhibition on the growth, as well as metastasis-related biological behaviors of HCC $[68,69]$.

\section{Genetic alterations of telomerase}

Telomerase, an RNA-dependent DNA polymerase, can maintain the telomeric length by acting as a reverse transcriptase. In humans, tumor cells escape programmed cell senescence through reactivation of telomerase $[70,71]$. These immortalized cells can compensate for telomeric shortening at each cell division, leading to progressive neoplastic evolution. Telomerase re-expression was found in $85 \%$ of malignant tumors $[72,73]$. Maybe HBV infection is merely a carcinogenic factor and is not related to the growth, infiltration, and metastasis of HCC. It is increasingly clear that oncogenesis is driven by telomerase activation, a ribonucleoprotein complex that adds telomeric repeats (hexa-nucleotide 5'-TTAGGG-3') to the ends of replicating chromosomes. Telomerase is a ribonucleoprotein composed of an essential RNA and a few proteins and is expressed in embryonic cell and in adult male germ line cells but undetected in normal somatic cells except proliferative cells of renewable tissues [74].

The expression of telomerase is important to cell proliferation, senescence, immortalization, and carcinogenesis. The hepatoma model displayed the dynamic expression of hepatic telomerase during HCC development and up to its highest
Fig. 5 Expressions of liver IGF-II or its gene transcription and diagnostic value of circulating IGFII. a IGF-II in distal cancerous tissues. b IGF-II in cancerous tissues. c IGF-II mRNA in HCC, paracancerous, and distal cancerous tissues. $\mathbf{d}$ The receiver operating characteristic curves of serum IGF-II in HCC with the area 0.823 for AFP and 0.771 for IGF-II

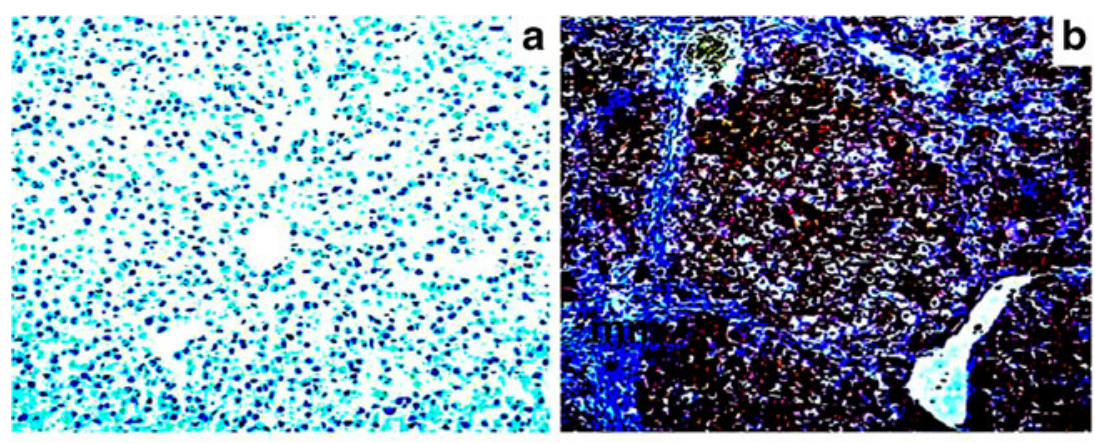

C
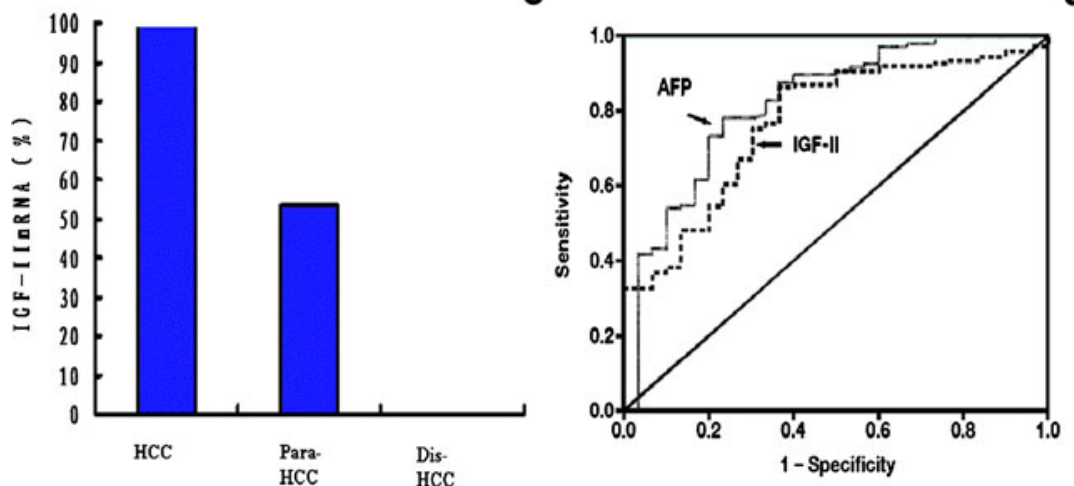
peak at the stage of $\mathrm{HCC}$ formation. Its activities were consistent with liver total RNA levels at the stages of degeneration, precancerosis, and cancerization of hepatocytes. The telomerase levels in HCC tissues were also significantly higher than those in their adjacent noncancerous tissues, but liver total RNA levels were lower in the former than those in the latter. Although the circulating telomerase of HCC patients was abnormally expressed among cases with chronic liver diseases, its activity was a nonspecific marker for HCC diagnosis, because the incidence was lower in control or in chronic liver diseases and $83 \%$ in HCC when absorbance was $>0.2$, respectively. If the value was $>0.6$, the incidence was $63 \%$ in $\mathrm{HCC}$ and none in any of the others except for two cases with liver cirrhosis [46], with AFP detection increasing the accuracy $(93 \%)$ for HCC diagnosis, suggesting that telomerase expression was associated with HCC development, and its abnormality could be a useful marker for diagnosis and prognosis of HCC [75, 76].

\section{Heat shock protein}

Heat shock protein (HSP) is a highly conserved protein produced under the perturbation or stressors of many physical and chemical factors. It participates in the complex formation of many proteins, contributes to the folding and extension of proteins as well as the assembly of polycomplex, functions in protein transport between cell organelles, and regulates the target proteins other than changes of their construction [77, 78]. Thus, it is defined as a molecular chaperone. HSPs are ubiquitous molecules induced in cells exposed to various stress conditions, including carcinogenesis. Previous studies have shown an upregulated expression of gp96 in tumor cells as an apoptosis inhibitor, abnormal HSP correlated with carcinogenesis, progression, and prognosis of HCC. HSP gp96 (or GRP94) as a putative high-density lipoprotein-binding protein in the liver and a member of the HSP90 family (HSP83, HSP84, HSP87, HSP90 gp96, etc.) binds the repertoires of peptides, thus eliciting peptide-specific $\mathrm{T}$ cell immune responses. It predominantly locates inside the endoplasmic reticulum with some cell surface expression in certain cancerous cells. Enhancement of intracellular HSP is closely related to the formation and development of HCC [79] and a vital marker indicating the progression and aggravation of HCC $[7,80]$.

HSP90 is required for the activity of HBV reverse transcriptase. The gp96 expression is increased as the HBVinduced disease progresses from chronic hepatitis to cirrhosis and then to HCC. The longevity of cirrhotic and HCC cells compared to normal hepatocytes is plausible to propose that increased gp96 expression in these tumor cells is closely related to the cell survival, thereof possibly by preventing cell apoptosis. The gp96 was strongly expressed in HCC (73.3 \%) and was weakly expressed in noncancerous tissues, correlated with the degree of tumor differentiation or size, but not with tumor number. The data of immunohistochemical analysis showed that $90 \%$ of HCC patients with positive HBV-DNA were strongly expressed for gp 96 , whereas only $46 \%$ of the patients with HBV-DNA-negative were positive for gp96 [81].

HSP70 and HSP27 among HSPs are of special relevance in cancer, inhibiting apoptosis and frequently staining in the cytoplasm and nuclei of tumor cells, but not in nonneoplastic hepatocytes. Immunoreactivity of HSP70 or HSP27 was observed in 56.3 and $61.9 \%$ of HCC; the former was correlated with high Ki-67-labeling indices (LIs), large tumor size, presence of portal vein invasion, and high tumor stage, and the latter was significantly related to the subgroup of HBVassociated HCCs, but not to others. Both HSP70 and HSP27 immunoreactivities showed no relation to Apotag LIs or p53 immunoreactivity. Expressions of HSP70 and HSP27 might play an important role in hepatocarcinogenesis, and HSP70, in particular, was closely related to the pathological parameters associated with HCC progression [82, 83].

\section{Circulating microRNAs}

miRNAs are small noncoding RNAs that function as endogenous silencers of numerous target genes [84, 85]. Hundreds of miRNAs have been identified in human genome. miRNAs are expressed in a tissue-specific manner and play important roles in cell proliferation, apoptosis, and differentiation of HCC. Aberrant expression of miRNAs may also contribute to the development and progression of HCC, and miRNAs play roles as tumor suppressors or oncogenes. $m i R-122$, let-7 family, and miR-101 are downregulated, and they are potential tumor suppressors of HCC. $m i R-221$ and $m i R-222$ are upregulated in HCC and may act as oncogenic miRNAs in hepatocarcinogenesis. miRNA expression profiling may be a powerful clinical tool for the diagnosis and regulation of miRNA expression which could be a novel therapeutic strategy for HCC $[86,87]$.

Many studies have shown that miRNAs play a crucial role in driving organ and tissue differentiation during embryogenesis and in the fine-tuning of fundamental biological processes. The role of miRNAs in HCC is analyzed for exploring the possible mechanisms by which they contribute to this neoplasm. Moreover, the possible role of circulating miRNAs as biomarkers, a field that needs urgent improvement in the clinical surveillance of $\mathrm{HCC}$, and the fascinating possibility of using them as therapeutic targets or drugs themselves [88] were also analyzed. Several miRNAs are involved in HBV or $\mathrm{HCV}$ replication and virus-induced changes, whereas others participate in multiple intracellular signaling pathways that modulate apoptosis, cell cycle checkpoints, and growth 
factor-stimulated responses. When disturbed, these pathways appear to result in malignant transformation and, ultimately, HCC development. It could also serve as indicators with respect to drug efficacy and be prognostic in HCC. Such biomarkers would assist in the stratification of HCC and help in direct personalized therapy [89].

\section{Perspectives}

Hepatoma has exhibited numerous genetic abnormalities as well as epigenetic alterations including modulation of DNA methylation [90, 91]. Molecular factors are involved in the process of HCC development and metastasis [92, 93]. Several laboratories have implicated constitutive activation of miRNA as one of the early key events involving in liver neoplastic progression [94, 95]. Further studies will permit us to analyze the mechanism of hepatocarcinogenesis and to pay attention to these areas [96]. However, the combination of pathological features and some biomarkers with high sensitivity and specificity for early diagnosis and metastasis of HCC seems to be more practical up to present.

Acknowledgments This work was supported by the grants from the Projects of Jiangsu Medical Science (HK201102, BL2012053), the Priority Academic Program Development of Jiangsu Higher Education Institution, the Nantong Society Undertaking and Technological Innovation (HS2012039), the Post-Doctor Scientific Funds (2012M521108, 2013M53139, JS2012-468), and the International S\&T Cooperation Program (2013DFA32150) of China.

Open Access This article is distributed under the terms of the Creative Commons Attribution License which permits any use, distribution, and reproduction in any medium, provided the original author(s) and the source are credited.

\section{References}

1. Yang JD, Roberts LR. Hepatocellular carcinoma: a global view. Nat Rev Gastroenterol Hepatol. 2010;7(8):449-58. PMID: 20628345.

2. El-Serag HB. Epidemiology of viral hepatitis and hepatocellular carcinoma. Gastroenterology. 2012;142(6):1264-73. PMID: 22537432.

3. Ni JY, Liu SS, Xu LF, Sun HL, Chen YT. Meta-analysis of radiofrequency ablation in combination with transarterial chemoembolization for hepatocellular carcinoma. World J Gastroenterol. 2013;19(24):3872-82. PMID: 23840128

4. Wei Z, Doria C, Liu Y. Targeted therapies in the treatment of advanced hepatocellular carcinoma. Clin Med Insights Oncol. 2013;7(1):87-102. PMID: 23761989.

5. Jain S, Singhal S, Lee P, Xu R. Molecular genetics of hepatocellular neoplasia. Am J Transl Res. 2010;2(1):105-18. PMID: 20182587.

6. Kawakami M, Koda M, Mandai M, Hosho K, Murawaki Y, Oda W, et al. Isolated metastases of hepatocellular carcinoma in the right atrium: case report and review of the literature. Oncol Lett. 2013;5(5): 1505-8. PMID: 23760591.
7. Block TM, Marrero J, Gish RG, Sherman M, London WT, Srivastava $\mathrm{S}$, et al. The degree of readiness of selected biomarkers for the early detection of hepatocellular carcinoma: notes from a recent workshop. Cancer Biomark. 2008;4(1):19-33. PMID: 18334731.

8. Volk ML, Hernandez JC, Su GL, Lok AS, Marrero JA. Risk factors for hepatocellular carcinoma may impair the performance of biomarkers: a comparison of AFP, DCP, and AFP-L3. Cancer Biomark. 2007;3(1):79-87. PMID: 17522429.

9. Hayashi E, Kuramitsu Y, Okada F, Fujimoto M, Zhang X, Kobayashi $\mathrm{M}$, et al. Protoemics profiling for cancer progression differential display analysis for the expression of intracellular proteins between regressive and progressive cancer cell lines. Proteomics. 2005;5(4): 1024-32. PMID: 15712240.

10. Chen F, Xue J, Zhou L, Wu S, Chen Z. Identification of serum biomarkers of hepatocarcinoma through liquid chromatography/ mass spectrometry-based metabonomic method. Anal Bioanal Chem. 2011;401(6):1899-904. PMID: 21833635.

11. Wu W, Yao DF, Yuan YM, Fan JW, Lu XF, Li XH, et al. Combined serum hepatoma-specific alpha-fetoprotein and circulating alpha-fetoprotein-mRNA in diagnosis of hepatocellular carcinoma. Hepatobiliary Pancreat Dis Int. 2006;5(4):538-44. PMID: 17085339.

12. Kohles N, Nagel D, Jüngst D, Durner J, Stieber P, Holdenrieder S. Prognostic relevance of oncological serum biomarkers in liver cancer patients undergoing transarterial chemoembolization therapy. Tumour Biol. 2012;33(1):33-40. PMID: 21931992.

13. Qu KZ, Zhang K, Li H, Afdhal NH, Albitar M. Circulating microRNAs as biomarkers for hepatocellular carcinoma. J Clin Gastroenterol. 2011;45(4):355-60. PMID: 21278583.

14. Wang HL, Anatelli F, Zhai QJ, Adley B, Chuang ST, Yang XJ. Glypican-3 as a useful diagnostic marker that distinguishes hepatocellular carcinoma from benign hepatocellular mass lesions. Arch Pathol Lab Med. 2008;132(11):1723-8. PMID: 18976006.

15. Mao YL, Yang HY, Xu HF, Sang XT, Lu X, Yang ZY, et al. Significance of Golgi glycoprotein 73, a new tumor marker in diagnosis of hepatocellular carcinoma: a primary study. Chin Med J. 2008;88(14):945-51. PMID: 18756964.

16. Hu JS, Wu DW, Liang S, Miao XY. GP73, a resident Golgi glycoprotein, is sensibility and specificity for hepatocellular carcinoma of diagnosis in a hepatitis B-endemic Asian population. Med Oncol. 2010;27(2):339-45. PMID: 19399652.

17. Imbeaud S, Ladeiro Y, Zucman-Rossi J. Identification of novel oncogenes and tumor suppressors in hepatocellular carcinoma. Semin Liver Dis. 2010;30(1):75-86. PMID: 20175035.

18. Zinkin NT, Grall F, Bhaskar K, Otu HH, Spentzos D, Kalmowitz B, et al. Serum proteomics and biomarkers in hepatocellular carcinoma and chronic liver disease. Clin Cancer Res. 2008;14(2):470-7. PMID: 18223221.

19. Nouso K, Kobayashi Y, Nakamura S, Kobayashi S, Takayama H, Toshimori J, et al. Prognostic importance of fucosylated alphafetoprotein in hepatocellular carcinoma patients with low alphafetoprotein. J Gastroenterol Hepatol. 2011;26(7):1195-200. PMID: 21410750.

20. Yuen MF, Lai CL. Serological markers of liver cancer. Best Pract Res Clin Gastroenterol. 2005;19(1):91-9. PMID:15757806.

21. Yoshida S, Kurokohchi K, Arima K, Masaki T, Hosomi N, Funaki T, et al. Clinical significance of lens culinaris agglutinin-reactive fraction of serum alpha-fetoprotein in patients with hepatocellular carcinoma. Int J Oncol. 2002;20(2):305-9. PMID: 11788893.

22. El-Serag HB, Kramer JR, Chen GJ, Duan Z, Richardson PA, Davila JA. Effectiveness of AFP and ultrasound tests on hepatocellular carcinoma mortality in HCV-infected patients in the USA. Gut. 2011;60(7):992-7. PMID: 21257990.

23. Li D, Mallory T, Satomura S. AFP-L3: a new generation of tumor marker for hepatocellular carcinoma. Clin Chim Acta. 2001;313(1): 15-9. PMID: 11694234. 
24. Kusaba T. Relationship between lens culinaris agglutinin reactive alpha-fetoprotein and biological features of hepatocellular carcinoma. Kurume Med J. 1998;45(1):113-20. PMID: 9658760.

25. Cheng HT, Chang YH, Chen YY, Lee TH, Tai DI, Lin DY. AFP-L3 in chronic liver diseases with persistent elevation of alphafetoprotein. J Chin Med Assoc. 2007;70(8):310-7. PMID: 17698430.

26. Miyaaki H, Nakashima O, Kurogi M, Eguchi K, Kojiro M. Lens culinaris agglutinin-reactive alpha-fetoprotein and protein induced by vitamin $\mathrm{K}$ absence II are potential indicators of a poor prognosis: a histopathological study of surgically resected hepatocellular carcinoma. J Gastroenterol. 2007;42(12):962-8. PMID: 18085353

27. Marubashi S, Nagano H, Wada H, Kobayashi S, Eguchi H, Takeda Y, et al. Clinical significance of alpha-fetoprotein mRNA in peripheral blood in liver resection for hepatocellular carcinoma. Ann Surg Oncol. 2011;18(8):2200-9. PMID: 21301972.

28. Zhang Y, Li Q, Liu N, Song T, Liu Z, Guo R, et al. Detection of MAGE1, MAGE-3 and AFP mRNA as multimarker by real-time quantitative PCR assay: a possible predictor of hematogenous micrometastasis of hepatocellular carcinoma. Hepatogastroenterology. 2008;55(88):2200 6. PMID: 19260505 .

29. Montaser LM, Abbas OM, Saltah AM, Waked IA. Circulating AFP mRNA as a possible indicator of hematogenous spread of HCC cells: a possible association with HBV infection. J Egypt Natl Canc Inst. 2007;19(1):48-60. PMID: 18839035.

30. Debruyne EN, Delanghe JR. Diagnosing and monitoring hepatocellular carcinoma with alpha-fetoprotein: new aspects and applications. Clin Chim Acta. 2008;395(1):19-26. PMID: 18538135.

31. Carr BI, Pancoska P, Branch RA. Significance of increased serum GGTP levels in HCC patients. Hepatogastroenterology. 2010;57(101): 869-74. PMID: 21033244

32. Wang NY, Zhang D, Zhao W, Fang GX, Shi YL, Duan MH. Clinical application of an enzyme-linked immunosorbent assay detecting hepatoma-specific gamma-glutamyl transferase. Hepatol Res. 2009;39(10):979-87. PMID: 19624768.

33. Ju MJ, Qiu SJ, Fan J, Zhou J, Gao Q, Cai MY, et al. Preoperative serum gamma-glutamyl transferase to alanine aminotransferase ratio is a convenient prognostic marker for Child-Pugh A hepatocellular carcinoma after operation. J Gastroenterol. 2009;44(6):635-42. PMID: 19387533

34. Morsi MI, Hussein AE, Mostafa M, El-Abd E, El-Moneim NA. Evaluation of tumour necrosis factor-alpha, soluble P-selectin, gamma-glutamyl transferase, glutathione $S$-transferase-pi and alpha-fetoprotein in patients with hepatocellular carcinoma before and during chemotherapy. Br J Biomed Sci. 2006;63(1):74-8. PMID: 16871999.

35. West MB, Hanigan MH. $\gamma$-Glutamyl transpeptidase is a heavily $N$ glycosylated heterodimer in HepG2 cells. Arch Biochem Biophys. 2010;504(2):177-81. PMID: 20831856.

36. Zhang JB, Chen Y, Zhang B, Xie X, Zhang L, Ge N, et al. Prognostic significance of serum gamma-glutamyl transferase in patients with intermediate hepatocellular carcinoma treated with transcatheter arterial chemoembolization. Eur J Gastroenterol Hepatol. 2011;23(9): 787-93. PMID: 21730869.

37. Yu ZJ, Yu JW, Cai W, Yuan HX, Li XY, Yuan Y, et al. Evaluation of HCPTd1, d14-double passaged intervening chemotherapy protocol for hepatocellular carcinoma. World J Gastroenterol. 2005;11(33): 5221-5. PMID: 16127757.

38. Yao DF, Huang ZW, Chen SZ, Huang JF, Lu JX, Xiao MB, et al. Diagnosis of hepatocellular carcinoma by quantitative detection of hepatoma-specific bands of serum gamma-glutamyltransferase. Am J Clin Pathol. 1998;110(6):743-9. PMID: 9844586.

39. Yao DF, Jiang DR, Huang ZW, Lu JX, Tao QY, Yu ZJ, et al. Abnormal expression of hepatoma specific $\gamma$-glutamyl transferase and alteration of $\gamma$-glutamyl transferase gene methylation status in patients with hepatocellular carcinoma. Cancer. 2000;88(4):761-9. PMID: 10679644.

40. Yao DF, Dong ZZ, Yao DB, Wu XH, Wu W, Qiu LW, et al. Abnormal expression of hepatoma-derived gamma-glutamyltransferase subtyping and its early alteration for carcinogenesis of hepatocytes. Hepatobiliary Pancreat Dis Int. 2004;3(4):564-70. PMID: 15567746.

41. Tang QY, Yao DF, Lu JX, Wu XH, Meng XY. Expression and alterations of different molecular form gamma-glutamyl transferase and total RNA concentration during the carcinogenesis of rat hepatoma. World J Gastroenterol. 1999;5(4):356-8 [ PMID: 11819467].

42. Filmus J, Capurro M. The role of glypican- 3 in the regulation of body size and cancers. Cell Cycle. 2008;7(18):2787-90. PMID: 18787398.

43. Shafizadeh N, Ferrell LD, Kakar S. Utility and limitations of glypican-3 expression for the diagnosis of hepatocellular carcinoma at both ends of the differentiation spectrum. Mod Pathol. 2008;21(8): 1011-8. PMID: 18536657.

44. Yao M, Yao DF, Bian YZ, Wu W, Yan XD, Yu DD, et al. Values of circulating GPC-3 mRNA and alpha-fetoprotein in detecting patients with hepatocellular carcinoma. Hepatobiliary Pancreat Dis Int. 2013;12(2):171-9. PMID: 23558072.

45. Nassar A, Cohen C, Siddiqui MT. Utility of glypican-3 and survivin in differentiating hepatocellular carcinoma from benign and preneoplastic hepatic lesions and metastatic carcinomas in liver fine-needle aspiration biopsies. Diagn Cytopathol. 2009;37(9):629 35. PMID: 19405109.

46. Yao M, Yao DF, Bian YZ, Zhang CG, Qiu LW, Wu W, et al. Oncofetal antigen glypican-3 as a promising early diagnostic marker for hepatocellular carcinoma. Hepatobiliary Pancreat Dis Int. 2011;10(3):289-94. PMID: 21669573.

47. Yan D, He Q, Chen Y, Wang L, Zhang X. Detection of $\alpha$-fetoprotein and glypican-3 mRNAs in the peripheral blood of hepatocellular carcinoma patients by using multiple FQ-RT-PCR. J Clin Lab Anal. 2011;25(2):113-7. PMID: 21438004.

48. Qiao SS, Cui ZQ, Gong L, Han H, Chen PC, Guo LM, et al. Simultaneous measurements of serum AFP, GPC-3 and HCCR for diagnosing hepatocellular carcinoma. Hepatogastroenterology. 2011;58(110-111):1718-24. PMID: 21940340.

49. Shirakawa H, Suzuki H, Shimomura M, Kojima M, Gotohda N, Takahashi S, et al. Glypican-3 expression is correlated with poor prognosis in hepatocellular carcinoma. Cancer Sci. 2009;100(8): 1403-7. PMID: 19496787.

50. Kandil D, Leiman G, Allegretta M, Trotman W, Pantanowitz L, Goulart R, et al. Glypican-3 immunocytochemistry in liver fineneedle aspirates: a novel stain to assist in the differentiation of benign and malignant liver lesions. Cancer. 2007;111(5):316-22. PMID: 17763368 .

51. Scharf JG, Dombrowski F, Ramadori G. The IGF axis and hepatocarcinogenesis. Mol Pathol. 2001;54(3):138-44. PMID: 11376124.

52. Blobe GC, Schiemann WP, Lodish HF. Role of transforming growth factor beta in human disease. N Engl J Med. 2000;342(18):1350-8. PMID: 10793168.

53. Bissell DM, Roulot D, George J. Transforming growth factor beta and the liver. Hepatology. 2001;34(5):859-67. PMID: 11679955.

54. Lee D, Chung YH, Kim JA, Lee YS, Lee D, Jang MK, et al. Transforming growth factor beta 1 overexpression is closely related to invasiveness of hepatocellular carcinoma. Oncology. 2012;82(1): 11-8. PMID: 22269311.

55. Divella R, Daniele A, Gadaleta C, Tufaro A, Venneri MT, Paradiso A, et al. Circulating transforming growth factor- $\beta$ and epidermal growth factor receptor as related to virus infection in liver carcinogenesis. Anticancer Res. 2012;32(1):141-5. PMID: 22213299.

56. Morris SM, Baek JY, Koszarek A, Kanngurn S, Knoblaugh SE, Grady WM. Transforming growth factor-beta signaling promotes hepatocarcinogenesis induced by p53 loss. Hepatology. 2012;55(1): 121-31. PMID: 21898503. 
57. Yamazaki K, Masugi Y, Sakamoto M. Molecular pathogenesis of hepatocellular carcinoma: altering transforming growth factor- $\beta$ signaling in hepatocarcinogenesis. Dig Dis. 2011;29(3):284-8. PMID: 21829019

58. Hoshida Y. Molecular signatures and prognosis of hepatocellular carcinoma. Minerva Gastroenterol Dietol. 2011;57(3):311-22. PMID:21769080.

59. Dong ZZ, Yao DF, Yao M, Qiu LW, Zong L, Wu W, et al. Clinical impact of plasma TGF-beta1 and circulating TGF-betal mRNA in diagnosis of hepatocellular carcinoma. Hepatobiliary Pancreat Dis Int. 2008;7(3):288-95. PMID: 18522884.

60. Dong ZZ, Yao DF, Zou L, Yao M, Qiu LW, Wu XH, et al. An evaluation of transforming growth factor-beta 1 in diagnosing hepatocellular carcinoma and metastasis. Zhonghua Gan Zang Bing Za Zhi. 2007;15(7):503-8. Chinese [PMID: 17669238].

61. Scharf JG, Braulke T. The role of the IGF axis in hepatocarcinogenesis. Horm Metab Res. 2003;35(11-12):685-93. PMID: 14710347.

62. Rehem RN, El-Shikh WM. Serum IGF-1, IGF-2 and IGFBP-3 as parameters in the assessment of liver dysfunction in patients with hepatic cirrhosis and in the diagnosis of hepatocellular carcinoma. Hepatogastroenterology. 2011;58(108-108):949-54. PMID: 21830422.

63. Cantarini MC, de la Monte SM, Pang M, Tong M, D'Errico A, Trevisani F, et al. Aspartyl-asparagyl beta hydroxylase overexpression in human hepatoma is linked to activation of insulin-like growth factor and notch signaling mechanisms. Hepatology. 2006;44(2):446-57. PMID: 16871543.

64. Wang Z, Ruan YB, Guan Y, Liu SH. Expression of IGF-II in early experimental hepatocellular carcinomas and its significance in early diagnosis. World J Gastroenterol. 2003;9(2):267-70. PMID: 12532445 .

65. Qiu LW, Yao DF, Zong L, Lu YY, Huang H, Wu W, et al. Abnormal expression of insulin-like growth factor-II and its dynamic quantitative analysis at different stages of hepatocellular carcinoma development. Hepatobiliary Pancreat Dis Int. 2008;7(4):406-11. PMID: 18693177.

66. Dong ZZ, Yao DF, Yao DB, Wu XH, Wu W, Qiu LW, et al. Expression and alteration of insulin-like growth factor II-messenger RNA in hepatoma tissues and peripheral blood of patients with hepatocellular carcinoma. World J Gastroenterol. 2005;11(30): 4655-60. PMID: 16094705.

67. Yao DF, Dong ZZ, Liu YH, Zhao L, Huang JF, Meng XY. Amplification of peripheral blood insulin-like growth factor IImRNA and its clinical significance in the diagnosis of hepatocellular carcinoma. Zhonghua Gan Zang Bing Za Zhi. 2003;11(11):695-6. Chinese [PMID: 14636457].

68. Qian J, Yao D, Dong Z, Wu W, Qiu L, Yao N, et al. Characteristics of hepatic IGF-II expression and monitored levels of circulating IGF-II mRNA in metastasis of hepatocellular carcinoma. Am J Clin Pathol. 2010;134(5):799-806. PMID: 20959664.

69. Dong ZZ, Yao DF, Wu XH, Shi GS, Qiu LW, Wu W, et al. Early diagnostic value of abnormal expression of insulin-like growth factor (IGF)-II and IGF-II mRNA in hepatocellular carcinoma patients. Zhonghua Gan Zang Bing Za Zhi. 2005;13(11):866-8. Chinese [PMID: 16313745].

70. Daniel M, Peek GW, Tollefsbol TO. Regulation of the human catalytic subunit of telomerase (hTERT). Gene. 2012;498(2):135-46. PMID:22381618.

71. Satyanarayana A, Manns MP, Rudolph KL. Telomeres and telomerase: a dual role in hepatocarcinogenesis. Hepatology. 2004;40(2): 276-83. PMID: 15368430.

72. Mu J, Wei LX. Telomere and telomerase in oncology. Cell Res. 2002;12(1):1-7. PMID: 11942406.

73. Durant ST. Telomerase-independent paths to immortality in predictable cancer subtypes. J Cancer. 2012;3(1):67-82. PMID: 22315652.
74. Lewis KA, Wuttke DS. Telomerase and telomere-associated proteins: structural insights into mechanism and evolution. Structure. 2012;20(1):28-39. PMID: 22244753.

75. Yao DF, Wu W, Yao M, Qiu LW, Wu XH, Su XQ, et al. Dynamic alteration of telomerase expression and its diagnostic significance in liver or peripheral blood for hepatocellular carcinoma. World J Gastroenterol. 2006;12(31):4966-72. PMID:16937491.

76. Wu W, Yao DF, Qiu LW, Wu XH, Yao M, Su XQ, et al. Abnormal expression of hepatomas and circulating telomerase and its clinical values. Hepatobiliary Pancreat Dis Int. 2005;4(4):544-9. PMID: 16286259

77. Ciocca DR, Calderwood SK. Heat shock proteins in cancer: diagnostic, prognostic, predictive, and treatment implications. Cell Stress Chaperones. 2005;10(2):86-103. PMID: 16038406.

78. Lu WJ, Lee NP, Fatima S, Luk JM. Heat shock proteins in cancer: signaling pathways, tumor markers and molecular targets in liver malignancy. Protein Pept Lett. 2009;16(5):508-16. PMID: 19442230.

79. Sakamoto M, Mori T, Masugi Y, Effendi K, Rie I, Du W. Candidate molecular markers for histological diagnosis of early hepatocellular carcinoma. Intervirology. 2008;51(1):42-5. PMID: 18544947.

80. Wu XH, Yao DF, Su XQ, Tai BJ, Huang H, Qiu LW, et al. Dynamic expression of rat heat shock protein gp96 and its gene during development of hepatocellular carcinoma. Hepatobiliary Pancreat Dis Int. 2007;6(6):616-21. PMID: 18086628.

81. Yao DF, Wu XH, Su XQ, Yao M, Wu W, Qiu LW, et al. Abnormal expression of HSP gp96 associated with HBV replication in human hepatocellular carcinoma. Hepatobiliary Pancreat Dis Int. 2006;5(3): 381-6. PMID: 16911935.

82. Luk JM, Lam CT, Siu AF, Lam BY, Ng IO, Hu MY, et al. Proteomic profiling of hepatocellular carcinoma in Chinese cohort reveals heatshock proteins (Hsp27, Hsp70, GRP78) up-regulation and their associated prognostic values. Proteomics. 2006;6(3):1049-57. PMID: 16400691.

83. Joo M, Chi JG, Lee H. Expressions of HSP70 and HSP27 in hepatocellular carcinoma. J Korean Med Sci. 2005;20(5):829-34. PMID: 16224158

84. Kojima K, Takata A, Vadnais C, Otsuka M, Yoshikawa T, Akanuma $\mathrm{M}$, et al. MicroRNA122 is a key regulator of $\alpha$-fetoprotein expression and influences the aggressiveness of hepatocellular carcinoma. Nat Commun. 2011;2(2):338. PMID: 21654638.

85. Gui J, Tian Y, Wen X, Zhang W, Zhang P, Gao J, et al. Serum microRNA characterization identifies miR-885-5p as a potential marker for detecting liver pathologies. Clin Sci. 2011;120(5):18393. PMID: 20815808.

86. Effendi K, Sakamoto M. Molecular pathology in early hepatocarcinogenesis. Oncology. 2010;78(2):157-60. PMID: 20389138.

87. Augello C, Vaira V, Caruso L, Destro A, Maggioni M, Park YN, et al. MicroRNA profiling of hepatocarcinogenesis identifies C19MC cluster as a novel prognostic biomarker in hepatocellular carcinoma. Liver Int. 2012;32(5):772-82. PMID: 22429613.

88. Giordano S, Columbano A. MicroRNAs: new tools for diagnosis, prognosis, and therapy in hepatocellular carcinoma? Hepatology. 2013;57(2):840-7. PMID: 23081718.

89. Zhao X, Yang Z, Li G, Li D, Zhao Y, Wu Y, et al. The role and clinical implications of microRNAs in hepatocellular carcinoma. Sci China Life Sci. 2012;55(10):906-19. PMID: 23108868.

90. Liao SF, Yang HI, Lee MH, Chen CJ, Lee WC. Fifteen-year population attributable fractions and causal pies of risk factors for newly developed hepatocellular carcinomas in 11,801 men in Taiwan. PLoS One. 2012;7(4):e34779. PMID: 22506050.

91. Gish RG, Lencioni R, Di Bisceglie AM, Raoul JL, Mazzaferro V. Role of the multi-disciplinary team in the diagnosis and treatment of hepatocellular carcinoma. Expert Rev Gastroenterol Hepatol. 2012;6(2):173-85. PMID: 22375523. 
92. Wong VW, Chan HL. Prevention of hepatocellular carcinoma: a concise review of contemporary issues. Ann Hepatol. 2012;11(3): 284-93. PMID: 22481445.

93. Abdalla MA, Haj-Ahmad Y. Promising candidate urinary MicroRNA biomarkers for the early detection of hepatocellular carcinoma among high-risk hepatitis C virus Egyptian patients. J Cancer. 2012;3(1):1931. PMID: 22211142.

94. Kohles N, Nagel D, Jüngst D, Durner J, Stieber P, Holdenrieder S. Relevance of circulating nucleosomes and oncological biomarkers for predicting response to transarterial chemoembolization therapy in liver cancer patients. BMC Cancer. 2011;11(1):202. PMID: 21615953.

95. Oda K, Ido A, Tamai T, Matsushita M, Kumagai K, Mawatari S, et al. Highly sensitive lens culinaris agglutinin-reactive $\alpha$-fetoprotein is useful for early detection of hepatocellular carcinoma in patients with chronic liver disease. Oncol Rep. 2011;26(5):1227-33. PMID: 21874252.

96. Petrelli A, Perra A, Schernhuber K, Cargnelutti M, Salvi A, Migliore C, et al. Sequential analysis of multistage hepatocarcinogenesis reveals that miR-100 and PLK1 dysregulation is an early event maintained along tumor progression. Oncogene. 2012;31(42):4517-26. PMID: 22249248. 